\title{
First Identification of IMP-1 Metallo- $\beta$-Lactamase in Delftia tsuruhatensis Strain CRS1243 Isolated From a Clinical Specimen
}

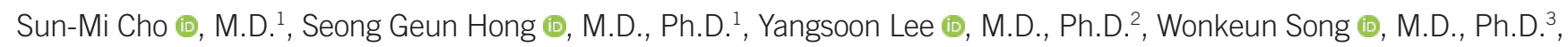

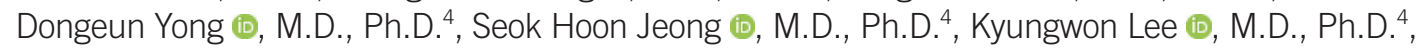
and Yunsop Chong (i), Ph.D. ${ }^{4}$

${ }^{1}$ Department of Laboratory Medicine, CHA Bundang Medical Center, CHA University, Seongnam, Korea; ${ }^{2}$ Department of Laboratory Medicine, Hanyang University College of Medicine, Seoul, Korea; ${ }^{3}$ Department of Laboratory Medicine, Hallym University College of Medicine, Seoul, Korea; ${ }^{4}$ Department of Laboratory Medicine and Research Institute of Bacterial Resistance, Yonsei University College of Medicine, Seoul, Korea

\section{Dear Editor,}

Delftia tsuruhatensis is a gram-negative bacillus that was first isolated from activated sludge collected from a domestic wastewater treatment plant in Tsuruhata, Japan [1]. The bacteria are motile, slightly curved, and short rods. The species is closely related to and often misidentified as Delftia acidovorans (formerly Comamonas acidovorans) in biochemical tests because of their shared characteristics $[1,2]$. However, the original D. tsuruhatensis isolate cannot utilize D-mannitol, whereas most D. acidovorans strains can [3]. We present the first report of an IMP-1 metallo- $\beta$-lactamase (MBL)-producing $D$. tsuruhatensis strain that was isolated from a clinical specimen. The Institutional Review Board of the CHA Bundang Medical Center, Seongnam, Korea, approved this study (approval number: 2020-04011-001) and waived the need for informed consent.

D. tsuruhatensis is typically susceptible to carbapenem [2, 4]; however, we isolated a carbapenem-resistant strain from a 65-yr-old man diagnosed as having stomach cancer who underwent total gastrectomy. On post-operative day 16, bacterial culture was performed because of onset of fever. A Delftia species (strain CRS1243) was isolated from the surgical drainage fluid.
The isolate was identified as D. acidovorans with 99\% probability using Vitek 2 GN cards (bioMérieux, Marcy-l'Étoile, France) and with a score of 2.40 using the MALDI Biotyper (Bruker Daltonics, Billerica, MA, USA). However, as the isolated bacteria were unable to metabolize D-mannitol, we performed 16S rRNA gene sequencing and identified the strain as $D$. tsuruhatensis (100\% identity with GenBank accession number HQ731453.1).

The isolate was suspected to produce carbapenemases based on routine antimicrobial susceptibility testing using Vitek AST N212 cards (bioMérieux). Antimicrobial susceptibility was determined according to the CLSI Minimum Inhibitory Concentration (MIC) Interpretive Standards for other non-Enterobacteriaceae using the broth microdilution method $[5,6]$. The isolate was not susceptible to amikacin (MIC > $64 \mu \mathrm{g} / \mathrm{mL}$ ), levofloxacin (8 $\mu \mathrm{g} / \mathrm{mL})$, ceftazidime ( $>16 \mu \mathrm{g} / \mathrm{mL})$, cefepime ( $>32 \mu \mathrm{g} / \mathrm{mL}$ ), ceftriaxone ( $>32 \mu \mathrm{g} / \mathrm{mL})$, and meropenem $(16 \mu \mathrm{g} / \mathrm{mL})$, but it was susceptible to piperacillin-tazobactam $(16 \mu \mathrm{g} / \mathrm{mL})$ and $\mathrm{mi}$ nocycline $(\leq 0.5 \mu \mathrm{g} / \mathrm{mL})$. The modified Hodge test result was positive, and in carbapenemase inhibition testing (Rosco Diagnostica A/S, Taastrup, Denmark), we observed enlarged inhibition zones when using disks containing meropenem supple-
Received: June 26, 2020

Revision received: September 23, 2020

Accepted: January 4, 2021

Corresponding author: Seong Geun Hong, M.D., Ph.D. Department of Laboratory Medicine, CHA Bundang Medical Center, CHA University, 59 Yatap-ro, Bundang-gu, Seongnam 13496, Korea Tel: +82-31-780-5463, Fax: +82-31-780-5476

E-mail: hlseo@cha.ac.kr

\section{(c) (1) $(9$}

\section{(C) Korean Society for Laboratory Medicine}

This is an Open Access article distributed under the terms of the Creative Commons Attribution Non-Commercial License (https://creativecommons.org/licenses/by-nc/4.0) which permits unrestricted non-commercial use, distribution, and reproduction in any medium, provided the original work is properly cited. 
mented with dipicolinic acid, indicating production of MBL. An expanded inhibition zone was also detected with disks containing meropenem supplemented with cloxacillin, but not with those containing boronic acid. Moreover, the cefoxitin-Hodge test result was negative. Based on these results, we concluded that this isolate was negative for AmpC $\beta$-lactamase activity.

Multiplex PCR was performed to detect the specific MBL. The specific primer pairs for the detection of the New Delhi MBL and São Paulo MBL were designed in this study and those for the detection of Verona integron-encoded MBL, imipenemase (IMP), Seoul IMP, and German IMP were selected from a previous report (Table 1). The sequence of the bacterial integron carrying the MBL-encoding gene was identified using primer walking (Table 1). We found that D. tsuruhatensis CRS1243 harbored a gene encoding blamp-1 within a class 1 integron located on a Tn402-like transposon. Between the 5'-conserved segment and the tni module, the gene cassettes included orfE, aac( $\left.6^{\prime}\right)$ 31-like, orfE, orfE, $\operatorname{aac}\left(6^{\prime}\right)-1 /, \operatorname{aac} A 7$, blaimp-1, $\operatorname{aac} A 7, \operatorname{aac}\left(6^{\prime}\right)-$ II, and qacE2 (Fig. 1). The nucleotide sequence of the class 1 integron has been deposited in GenBank under accession number KC170993. While a class 3 integron has been previously identified in a $D$. tsuruhatensis strain, the gene cassettes were not evaluated functionally [12]. To determine the location of the class 1 integron, we performed plasmid extraction and conjugation [13]. However, we could not identify the band corresponding to the plasmid DNA, and the carbapenem resistance was not transferred to sodium azide-resistant Escherichia coli J53.

Cases of human infection with D. tsuruhatensis are rare [2]. In 2011, D. tsuruhatensis was identified as the etiologic agent of a human catheter-related infection; since then, it has also been associated with other human infections [2]. Recently, Fenollar, et al. [4] identified D. tsuruhatensis as an emerging opportunistic pathogen that should be considered as a cause of infection in patients with underlying disease and those using intravascular devices. The $D$. tsuruhatensis strain identified in this study was isolated twice in five days from pure cultures from surgical drainage fluid. Treatment with ciprofloxacin, an empirical antibi-

Table 1. Primers used for the PCR analysis of metallo- $\beta$-lactamase genes and primer walking

\begin{tabular}{|c|c|c|}
\hline Primer & Sequence $\left(5^{\prime} \rightarrow 3^{\prime}\right)$ & References \\
\hline NDM-F1 & GCC CAA TAT TAT GCA CCC GG & This study \\
\hline NDM-R & CGG AAT GGC TCA TCA CGA TC & This study \\
\hline SPM-NF & TGC GGG AGC GCC ATT GTC TG & This study \\
\hline SPM-NR & TTC CAC CCG TGC CGT CCA AA & This study \\
\hline VIM-F & GAT GGT GTT TGG TCG CAT A & 7 \\
\hline VIM-R & CGA ATG CGC AGC ACC AG & 7 \\
\hline IMP-F & GGA ATA GAG TGG CTT AAY TCT C & 7 \\
\hline IMP-R & CCA AAC YAC TAS GTT ATC T & 7 \\
\hline SIM-F & TAC AAG GGA TTC GGC ATC G & 7 \\
\hline SIM-R & TAA TGG CCT GTT CCC ATG TG & 7 \\
\hline GIM-F & TCG ACA CAC CTT GGT CTG AA & 7 \\
\hline GIM-R & AАC TТ САA CTT TGC CAT GC & 7 \\
\hline INT1-5CS & GGC ATC CAA GCA GCA AGC & 8 \\
\hline intl1-1F & ACA TGC GTG TAA ATC ATC GTC G & 9 \\
\hline attl-R & CПT TGT TाT AGG GCG ACT GC & This study \\
\hline aac6-F1 & GCT CGT TGA GAT GCT GTT CA & This study \\
\hline aacA7-R & GAA GCA GCG TAC TTG AGC AA & This study \\
\hline IMP-1R & ССТ ПTA ACC GCC TGC TCT AAT G & 10 \\
\hline IMP14 & AGG CGT GCT GCT GCA ACG ACT TGT & 11 \\
\hline qacEd1-R & TGA GCC CCA TAC CTA CAA AGC & 9 \\
\hline qacE2-R & ATT TGA GTG TCA GCG ACA GG & This study \\
\hline TniR-1 & GTG TTC GGT ATT TIT GCC GC & This study \\
\hline TniR-2 & GTA ATC CCG AGT TCT TCG CA & This study \\
\hline TniQ-1 & TGT GGT TC GAC ПTC ПTC GC & This study \\
\hline TniQ-2 & GAC CAG AAT AGC TाT GCC TG & This study \\
\hline TniQ-1M & TGT GGT TTC GAC TGC TAC GC & This study \\
\hline TniB-1 & GGA AAT GGA GCA ACT GGC T & This study \\
\hline TniB-2 & TाT CCA ACT GGT CAT CGG AG & This study \\
\hline TniB-1M & AGA AAT GGA ACA ACT GGC G & This study \\
\hline TniA-1 & TAG AGC GCT GGC TCA CAT T & This study \\
\hline TniA-2 & GGA TGT GGT CGA TGA CAA AG & This study \\
\hline
\end{tabular}

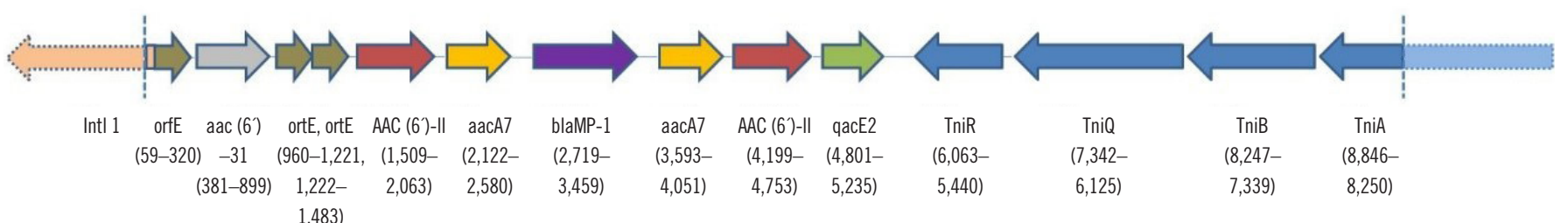

Fig. 1. Schematic representation of the 8,846-bp partial DNA sequence of the class 1 integron containing bla|mP-1 within a Tn402-like module in Delftia tsuruhatensis CRS1243. 
otic was started; however, piperacillin-tazobactam was administered after confirmation of the antibiotic susceptibility results. The patient's fever subsided one day after initiation of the treatment.

To the best of our knowledge, this is the first report of IMP-1 $\mathrm{MBL}$ production from a $D$. tsuruhatensis strain. Our findings suggest that clinical microbiologists need to be aware of $D$. tsuruhatensis as a potential cause of opportunistic infections. We note that the blaımp-1 gene linked to a mobile element might spread among Delftia or other bacterial species.

\section{ACKNOWLEDGEMENTS}

None.

\section{AUTHOR CONTRIBUTIONS}

Hong SG conceptualized and designed the study and coordinated the drafting of the manuscript. Hong SG performed the microbiologic test and PCR work. Hong SG, Cho SM, and Lee Y performed data analysis and wrote the manuscript. Song $\mathrm{W}$, Yong D, Jeong SH, Lee $\mathrm{K}$, and Chong Y supervised the study, reviewed and commented on the manuscript, and approved the final draft. All authors read and approved the final manuscript.

\section{CONFLICTS OF INTEREST}

The authors declare no conflicts of interest.

\section{RESEARCH FUNDING}

None.

\section{ORCID}

Sun-Mi Cho
Seong Geun Hong
Yangsoon Lee
Wonkeun Song
Dongeun Yong

https://orcid.org/0000-0003-0528-7023 https://orcid.org/0000-0001-9670-6777 https://orcid.org/0000-0003-3821-3741 https://orcid.org/0000-0001-5056-9033 https://orcid.org/0000-0002-1225-8477
Seok Hoon Jeong https://orcid.org/0000-0001-9290-897X Kyungwon Lee Yunsop Chong https://orcid.org/0000-0003-3788-2134 https://orcid.org/0000-0001-6754-6073

\section{REFERENCES}

1. Shigematsu T, Yumihara K, Ueda Y, Numaguchi M, Morimura S, Kida K. Delftia tsuruhatensis sp. nov., a terephthalate-assimilating bacterium isolated from activated sludge. Int J Syst Evol Microbiol 2003;53:147983.

2. Preiswerk B, Ullrich S, Speich R, Bloemberg GV, Hombach M. Case report human infection with Delftia tsuruhatensis isolated from a central venous catheter. J Med Microbiol 2011;60:246-8.

3. Jorgensen NO, Brandt KK, Nybroe O, Hansen M. Delftia lacustris sp. nov., a peptidoglycan-degrading bacterium from fresh water, and emended description of Delftia tsuruhatensis as a peptidoglycan-degrading bacterium. Int J Syst Evol Microbiol 2009;59:2195-9.

4. Ranc A, Dubourg G, Fournier PE, Raoult D, Fenollar F. Delftia tsuruhatensis, an emergent opportunistic healthcare-associated pathogen. Emerg Infect Dis 2018;24:594-6.

5. CLSI. Performance standards for antimicrobial susceptibility testing; approved standard. CLSI M100-S28. Wayne, PA: Clinical and Laboratory Standards Institute. 2018

6. CLSI. Methods for dilution antimicrobial susceptibility tests for bacteria that grow aerobically; approved standard. CLSI M7-A11. Wayne, PA: Clinical and Laboratory Standards Institute. 2018.

7. Ellington MJ, Kistler J, Livermore DM, Woodford N. Multiplex PCR for rapid detection of genes encoding acquired metallo-beta-lactamases. J Antimicrob Chemother 2007;59:321-2.

8. Sandvang D, Aarestrup FM, Jensen LB. Characterisation of integrons and antibiotic resistance genes in Danish multiresistant Salmonella enterica Typhimurium DT104. FEMS Microbiol Lett 1997;157:177-81.

9. Zhao WH, Hu ZQ. IMP-type metallo- $\beta$-lactamases in Gram-negative bacilli: distribution, phylogeny, and association with integrons. Crit Rev Microbiol 2011;37:214-26.

10. Jeong SH, Bae IK, Park KO, An YJ, Sohn SG, Jang SJ, Sung KH, Yang KS, Lee K, Young D, Lee SH. Outbreaks of imipenem-resistant Acinetobacter baumannii producing carbapenemases in Korea. J Microbiol 2006;44:423-31.

11. Chu YW, Afzal-Shah M, Houang ET, Palepou MI, Lyon DJ, Woodford N, Livermore DM. IMP-4, a novel metallo-beta-lactamase from nosocomia Acinetobacter spp. collected in Hong Kong between 1994 and 1998. Antimicrob Agents Chemother 2001;45:710-4.

12. Xu H, Davies J, Miao V. Molecular characterization of class 3 integrons from Delftia spp. J Bacteriol 2007;189:6276-83.

13. Walsh TR, Weeks J, Livermore DM, Toleman MA. Dissemination of NDM-1 positive bacteria in the New Delhi environment and its implications for human health: an environmental point prevalence study. Lancet Infect Dis 2011;11:355-62. 